\title{
Materialismo histórico e dialético em pesquisas do campo curricular: o ensino de História no curso de Pedagogia
}

\author{
Francisco Thiago Silva* \\ Centro Universitário Projeção
}

Lívia Freitas Fonseca Borges**

Universidade de Brasília

Resumo $\mathrm{O}$ presente artigo resulta de pesquisa acadêmica que investigou o espaço curricular do ensino de História em Instituições de Educação Superior privadas no curso de licenciatura em Pedagogia. Tomando como premissa a ideia de que analisar o objeto proposto a partir da tese - de que o ensino de História deva ser relevante nos currículos de formação do pedagogo - direciona esses escritos para a análise reflexiva sob a lente teórico-metodológica do materialismo histórico dialético - MHD. Não se assume uma postura de concebê-lo como doutrina, reconhece-se seus limites, mas admite-se que ainda é a tendência que melhor se aproxima dos anseios provocados pela própria teoria crítica de currículo. O objetivo do texto é apresentar elementos epistemológicos e metodológicos - por meio de revisão crítica de literatura - que garantam uma refinada utilização do método de Marx, com as devidas proporções, aplicado ao campo do currículo, sobretudo na esteira das teorias críticas. $\mathrm{O}$ objeto teórico aqui proposto é apenas para ilustrar de que forma as categorias teóricas da dialética marxiana e marxistas, como contradição, totalidade e prática social podem ser aplicadas em estudos dessa natureza.

PALAVRAS-CHAVE: Materialismo histórico e dialético; Currículo; Ensino de História. 


\title{
Dialectical and historical materialism in curricular field searches: the teaching of History in the course of Pedagogy
}

\begin{abstract}
This article results from academic research that investigated the curricular area of history teaching in private higher education institutions in the course of degree in pedagogy. Taking as premise the idea that analyze the proposed object from the thesis-that the teaching of History should be relevant in the curricula of teacher training-directs these writings to the reflective analysis under the methodological-theoretical lens of historical materialism dialectic - MHD. Assumes a posture of conceiving him as doctrine, recognized their limits, but admits that it's still the trend that better approaches the anxieties caused by the critical theory of curriculum. The aim of the text is to present epistemological and methodological elements-through critical review of literature-which guarantee a refined use of Marx's method, with the due proportions, applied to the field of curriculum, especially in the wake of critical theories. The theoretical object proposed here is only to illustrate how the theoretical categories of Marxian and Marxist dialectic, as contradiction, totality and social practice can be applied to studies of this nature.
\end{abstract}

KEYWORDS: Dialectical and historical materialism; Curriculum; History teaching.

\section{Introdução}

Embora o campo da pesquisa acadêmica em nível de pós-graduação stricto sensu tenha crescido em números de dissertações e teses concluídas, (80.916 em 2016 $)$ no país, ainda verificam-se algumas fragilidades, para além das de ordem estrutural que infelizmente cercam o trabalho docente universitário.

Em muitas áreas de produção do conhecimento no âmbito dos cursos de mestrado e doutorado, o campo das Ciências Humanas e Sociais permanece, embora tenha avançado, com muitos dilemas e contradições que povoaram sua gênese, como por exemplo, as eventuais dificuldades em estabelecer conexão entre objeto, tema, método, metodologia e epistemologias nascidas da imersão do pesquisador com a própria investigação proposta. Ciências como a Sociologia, a Antropologia e a Educação, que são essencialmente sociais, vez ou outra são julgadas e acusadas de não avançarem teórica e metodologicamente, sobretudo o campo educacional, que diferentemente de outras ciências, se debruça sobre a prática educativa em suas diferentes manifestações.

A aposta que é feita neste artigo é de que a ausência de perenidade na apropriação metódica para fomentar a produção de conhecimento científico na esteira educacional, encontra seu imbróglio exatamente na superficialidade com a qual muitos mestrandos e doutorandos se veem obrigados, por ter que cumprir cada vez mais metas de produtividade estabelecidas por seus programas e pela CAPES. 
Em razão dessa situação, tornou-se relevante publicizar em forma de reflexão teórica, de que forma uma pesquisa educacional pode valer-se do materialismo histórico dialético - vale ressaltar que isso poderia ser feito sob o prisma de qualquer outro método de pesquisa - para alimentar reflexões seguras e consistentes sobre o fenômeno educativo, nesse caso, tomou-se o campo do currículo como cenário de estudos, com todas as suas particularidades e contradições, concebendo já de início como território em disputa e contestado, a partir das teorias críticas (PUCCI, 2007; SILVA, 2011), por esse motivo a adesão ao MHD.

$\mathrm{O}$ artigo está estruturado da seguinte maneira: uma primeira parte discute o uso e a atualidade do MHD em pesquisas educacionais e por fim, apresenta-se um exemplo de pesquisa que alinhou seu objeto (do campo do currículo) ao método de Marx.

\section{Materialismo histórico dialético na pesquisa educacional}

A obra referencial de Cury (1989) foi um marco na produção acadêmica por confirmar o status científico do campo pedagógico enquanto ciência, em que é possível promover a criação de conhecimento por meio da exploração das categorias oriundas do materialismo histórico dialético:

A educação é, então, uma atividade humana partícipe da totalidade da organização social. Essa relação exige que se a considere como historicamente determinada por um modo de produção capitalista, ela tem uma especificidade que só é inteligível no contexto das relações sociais resultantes dos conflitos das duas classes fundamentais (p. 13).

Reconhecem-se também muitos avanços, principalmente após os anos de 1970, quando os Programas de Pós-Graduação em Educação deram um salto em quantidade e qualidade. Cury (1989) reconhece que a produção do conhecimento nesta área contribui para muitos grupos sociais que estiveram marginalizados nos processos de dominação nesse país. Não é trivial que, no Manifesto do Partido Comunista, Marx e Engels [1848] (2008), defendam ser a própria classe trabalhadora quem deva decidir os rumos da educação de seus próprios filhos, a começar pelo acesso gratuito a uma educação pública vinculada ao trabalho.

Concorda-se com a assertiva de Triviños (2011, p. 14) ao definir a finalidade da pesquisa educacional em países como o Brasil: "[...] servir aos processos de transformação da essência da realidade social que experimentamos", sobretudo porque a teoria social de Marx, resguardadas as proporções e temporalidades, era vinculada a um processo revolucionário.

Tendo em vista a concepção de que estes escritos devam atender aos interesses de um projeto contra-hegemônico, estabelece-se ligação com os argumentos de Cury (1989, p. 76): "[...] nos momentos em que as classes populares exerceram mais pressão sobre o poder, percebe-se quase sempre a luta pela educação. Esta última torna-se, pois, expressão da luta de classes". 
A devida apropriação do objeto a ser averiguado em todas as dimensões possíveis e conexões com as diferentes áreas do saber, e mesmo o domínio dos quadros de coerência e teoria/epistemologia de pesquisa não garantem uma fidedigna apropriação do real que foi teorizado pelos intelectuais.

Pesquisas com base no materialismo histórico dialético, como esta, reconhecem o avanço em Marx, na verdade o seu legado materialista é a tentativa de superação do mundo real, mas também não é uma aproximação da realidade infalível, pois toda teoria apresenta fragilidades e não pode, se deseja tornar-se consistente, fechar-se em si mesma ou tomar-se profissão de fé:

[...] o método materialista dialético não pode ser entendido de forma mecânica, descompromissado com a superação do mundo material, utilizando-o de forma especulativa e não engajada numa práxis revolucionária, pois isso seria uma contradição epistemológica, ontológica e ética (MORAES, 2014 p. 96).

É importante neste momento do texto, pontuar os conceitos centrais que devem gravitar em torno de qualquer pesquisa científica, neste caso sob o prisma dos escritos de Marx. Para as delineações do que seria ciência em Marx, apropria-se dos escritos de um importante estudioso marxista: Renault (2010), que destacou sua enfática defesa de que Marx professava a supremacia da racionalidade sob a filosofia. Para ele, a ciência

Interpretada por Marx como um processo dinâmico de aquisição da verdade, a ciência é, em parte, louvada pela superioridade de sua racionalidade sobre a da filosofia e, em parte, por seu potencial crítico e desmistificador, que autoriza a identificação entre ciência e crítica, [...] o que toda ciência tem de próprio é ultrapassar a aparência para apreender a essência (p. 16).

Autores como Gil (2009) e Triviños (2011) demonstram as características e fragilidades de epistemologias de pesquisas como o positivismo, a fenomenologia e a dialética. Embora se entenda as contribuições iniciais da ciência positivista em avançar na produção do conhecimento humano, a partir da própria razão humana e o distanciamento das explicações mágico-metafísicas, concorda-se que sua utilização no campo educacional apresenta entraves clássicos para a pesquisa, como a suposição de neutralidade do pesquisador e o não compromisso em propor uma saída transformadora para o fenômeno observado.

Tais críticas foram elencadas mais detalhadamente pelos teóricos da chamada Escola de Frankfurt, fundada em 1924: Theodor Adorno, Max Horkheimer, Walter Benjamin, Herbert Marcuse, Leo Löwenthal, Erich Fromm e Jürgen Habermas, em particular os três primeiros. Este grupo de intelectuais propunha revisitar as obras de Marx e constituir as bases da Teoria Crítica (PUCCI, 2007) na qual categorias como o capitalismo, a sociedade e a cultura do século XX deveriam ser reinterpretadas à luz da epistemologia marxiana em que "[...] a razão só pode ser defendida pela via de uma crítica a ela mesma" (GANEM, 2012, p. 95) e a crítica deve-se dar ao objeto pesquisado: a sociedade liberal capitalista. 
Antes de prosseguir com o estudo teórico do método de Marx, é relevante justificar a sua ligação com o campo curricular, espaço que abriga o objeto dessa pesquisa.

$\mathrm{Na}$ concepção de Silva (2011), as teorias de currículo são classificadas a partir de três perspectivas: tradicionais, críticas e pós-críticas. As primeiras repousam no positivismo, e concebem a educação e a organização do conhecimento (currículo) como processo mecânico e de caráter linear/rígido, que tem por objetivo ajustar os sujeitos ao mundo capitalista. Suas palavras-chave são: ensino (mera preocupação na transmissão, diferente do ensino com intenção na aprendizagem, foco desta tese), aprendizagem, avaliação, metodologia, didática, organização, planejamento, eficiência e objetivos. $\mathrm{Na}$ contramão destas, inserem-se as teorias críticas que tencionam discutir o uso político dos conhecimentos curriculares para reverter às desigualdades sociais nascidas, sobretudo, no seio do modo de produção capitalista. As últimas estão localizadas na perspectiva da pós-modernidade e focalizam nos sujeitos, na linguagem e no discurso a luta pela entrada no currículo de temas como: "Identidade, alteridade, diferença, subjetividade, significação e discurso, saber-poder, representação, cultura, gênero, raça-etnia e sexualidade" (p. 17).

Não se trata de disputas teóricas entre essas visões curriculares, elas coexistem e funcionam como possibilidade de estruturação da organização do trabalho pedagógico, contudo, as teorias críticas de currículo, que são sustentadas em sua maioria pelo marxismo, refutam a ideia de um currículo estático (tradicional) e questionam a relatividade das propostas pós-críticas.

A teoria crítica curricular compreende a escola como espaço dinâmico e social que traz as contradições da sociedade capitalista a partir das seguintes categorias: "Ideologia, reprodução cultural e social, poder, classe social, capitalismo, relações sociais de produção, conscientização, emancipação e libertação, currículo oculto e resistência" (SILVA, 2011, p. 17). Essa série de conceitos deve levar ao questionamento das desigualdades existentes e contribuir para a aquisição de conhecimentos sistematizados no espaço curricular que elevem a participação dos sujeitos em todas as esferas do poder político, garantindo sua emancipação.

Esse texto ancora-se na concepção de emancipação da classe operária desenvolvida por Gramsci (1982), em que a luta dos trabalhadores só ganha significado se unir mobilização acadêmica na escola unitária e junção de ideias e de pessoas nos partidos políticos. São autores de sua própria história, conscientes, críticos e emancipados.

A opção pelas teorias críticas de currículo leva à necessidade de refletir acerca das possibilidades de análise metodológica que o método marxiano de pesquisa oferece, e a partir dele, compreende-se que se liga a um projeto revolucionário de sociedade que passa por uma reconfiguração do campo educacional, quiçá do currículo, por isso é essencial caracterizar e refletir sobre como produzir conhecimentos coerentes com a ótica de Marx é singular para a emancipação humana. 
Marx (1818-1883) não se debruçou sobre um método de pesquisa, pois seu pensamento era de natureza ontológica e não epistemológica, conforme Lukács (1979) confirma, ao defender que Marx não escreveu ou deixou uma teoria lógica, deixou a lógica d'O Capital.

Embora alguns intelectuais, como o próprio Lukács (1979), não confirmem que o filósofo tenha se concentrado numa elaboração minuciosa sobre seu método de pesquisa, reconhece-se a visão de outros grupos, como os influenciados por Saviani (2010), que alegam que o filósofo tenha dedicado um bom tempo para descrever e até iniciar um discurso metodológico acerca do materialismo histórico dialético.

As evidências para este posicionamento são encontradas, inicialmente nas obras do próprio Marx, por exemplo:

Cabe à investigação apropriar-se da matéria em todos os seus pormenores, analisar as diversas formas do seu desenvolvimento e descobrir a sua relação íntima. É somente depois de concluída esta tarefa que o movimento real pode ser exposto no seu conjunto. Se eu conseguir chegar a esse ponto, de tal modo que a vida da matéria se reflitcta na sua reprodução ideal, isso pode levar a acreditar numa construção a priori $[. .$.$] o movimento do pensamento é apenas o$ reflexo do movimento real, transposto e traduzido no cérebro do homem (MARX, [1867], 1974, p. 9-10).

O método marxiano surge depois de quinze anos de investigação, e suas bases estão descritas em poucas páginas na "Introdução" redigida em 1857, na obra de 1857-1858, Elementos fundamentais para a crítica da economia política-Rascunhos.

Marx constrói seu cabedal teórico a partir de três frentes: o idealismo clássico alemão, sobretudo na obra de Hegel, embora posteriormente irá contrapor-se à sua lógica; o socialismo utópico de Saint-Simon e a economia política inglesa.

A partir de Triviños (2011), existe o entendimento de que o materialismo dialético é a base filosófica do marxismo e "[...] não só tem como base de seus princípios a matéria, a dialética e a prática social, mas também aspira ser a teoria orientadora da revolução do proletariado" (p. 51).

Diante desta afirmação, chega-se à concepção do materialismo histórico como ciência filosófica do próprio marxismo. Embora não haja unanimidade nos seguidores de Marx no que diz respeito às categorias e leis do materialismo histórico dialético, os continuadores da obra do alemão - os consistentes - são enfáticos ao defender que uma pesquisa assentada nesse método não pode prender-se em orientações panfletárias (FREITAG, 1993), já que é o próprio objeto a ser estudado que irá direcionar a dinâmica de escrita da síntese.

Não se refere a apropriações sem critérios da realidade, mas sim na observação de um rigor teórico que deve primar pela seriedade e originalidade da pesquisa, sabendo que o materialismo histórico dialético usado em trabalhos acadêmicos deve apresentar um dinamismo que salte aos olhos do leitor, e não uma mera descrição de um tratado ou um epítome teórico. 
Para Netto (2011), pode-se retirar uma prévia reflexão metodológica do próprio Marx a respeito do conceito do seu método, pois

Marx não nos apresentou o que "pensava" sobre o capital, a partir de um sistema de categorias previamente elaboradas e ordenadas conforme operações intelectivas: ele (nos) descobriu a estrutura e a dinâmica reais do capital; não lhe "atribuiu ou "imputou" uma lógica: extraiu da efetividade do movimento do capital a sua (própria, imanente) lógica. [....] o método implica, pois, para Marx, uma determinada posição (perspectiva) do sujeito que pesquisa: aquela em que se põe o pesquisador para, na sua relação com objeto, extrair dele as suas múltiplas determinações (NETTO, 2011, p. 52-53).

Apresenta-se mais um possível conceito para o método dialético:

[...] um método que permite uma apreensão radical (que vai à raiz) da realidade, enquanto práxis, isto é, unidade de teoria e prática na busca da transformação e de novas sínteses no plano do conhecimento e no plano da realidade histórica, [...] é uma postura, um método de investigação e uma práxis, um movimento de superação e de transformação. Há, pois, um tríplice movimento: de crítica, de construção do conhecimento 'novo', e da síntese no plano do conhecimento e da ação (FRIGOTTO, 2010, p. 79-86).

Existe um desdobramento das obras originais de Marx e Engels, a despeito dos trechos que trazem uma interpretação dos autores sobre seu percurso metodológico. No prefácio de [1859] da obra "Para a análise crítica da economia política", Marx legitima a importância do esforço de anos de seus trabalhos para que se chegue a determinadas conclusões: "[...] demonstrar que as minhas opiniões, sejam elas julgadas como forem e por menos que coincidam com os preconceitos interesseiros das classes dominantes, são o resultado duma investigação conscienciosa e de muitos anos" (1978, p. 2).

Mais pistas são encontradas em relação ao trajeto epistemológico e metodológico de Marx - agora em parceria com Engels, inclusive o alerta para a não tomada dogmática de suas teorias: "As premissas com que começamos não são arbitrárias, não são dogmas, são premissas reais, e delas só na imaginação se pode abstrair. existe com o resto da natureza" (MARX;ENGELS, 1982[1846] p. 3-4).

Em outro momento da obra "A ideologia Alemã", Marx e Engels apresentam sua essência da concepção materialista da história, reforçando o argumento anterior de que o ser humano só pode ser compreendido nas intensas e constantes relações que mantém com a natureza e com o mundo material, em seus vários âmbitos, sobretudo sendo o ser social. É por meio dessa complexa análise que é possível conhecer a própria estrutura social e a existência do Estado, a saber:

A estrutura social e o Estado decorrem constantemente do processo de vida de determinados indivíduos; mas destes indivíduos não como eles poderão parecer na sua própria representação ou na de outros, mas como eles são realmente, ou seja, como agem, como produzem materialmente, como trabalham, portanto, em determinados limites, premissas e condições materiais que não dependem da sua vontade (ibidem, p. 18-19). 
Os filósofos delineiam, a partir destas premissas, de que maneira é possível abstrair as leis, categorias e a própria essência do fenômeno estudado, contudo eles alertam que não é a consciência que determina a vida humana social, mas é a própria vida que determina a consciência:

[...] parte-se dos homens realmente activos, e com base no seu processo real de vida apresenta-se também o desenvolvimento dos reflexos [Reflexe] e ecos ideológicos deste processo de vida. Também as fantasmagorias no cérebro dos homens são sublimados necessários do seu processo de vida material empiricamente constatável e ligado a premissas materiais. A moral, a religião, a metafísica, e a restante ideologia, e as formas da consciência que lhes correspondem, não conservam assim por mais tempo a aparência de antinomia. (MARX; ENGELS, 1982[1846], p. 19).

O trabalho de pesquisa à luz do materialismo histórico dialético impulsiona a produção de uma síntese do que Marx chamou de "concreto pensado", resguardadas as advertências do próprio autor com relação à tentativa de compreender o fenômeno, que só poderá ser revelado, após exaurir-se suas múltiplas determinações, o resultado é a própria síntese:

No "final" desse processo, ter-se-á, então, não mais um concreto figurado e abstrato (porque pouco se sabia dele), mas, sim, um "concreto" pensado e abstrato (mas agora abstrato enquanto pensamento, enquanto compreensão mental que se tem dele; não mais abstrato porque vazio, porque o que se sabia dele era muito superficial e genérico). Uma aproximação significativa da essência do fenômeno, do que ele é (não do que ele aparentava ser, no início) (MARX, 1989, p.229).

Netto (2011) esclarece que Marx não traz em seus escritos um conjunto de regras, porque o método não pode ser encarado como um conjunto de regras frias e prontas que se aplicam a qualquer objeto, pois "[...] é a estrutura e a dinâmica do objeto que comandam os procedimentos do pesquisador" (NETTO, 2011, p. 52).

Embora se saiba que o método de pesquisa não possa ser reduzido a um dogma, Netto (2011) recomenda ainda observar alguns pressupostos para os pesquisadores desejosos em dinamizar a construção de seus objetos de pesquisa sob a ótica do materialismo histórico dialético: é a dinâmica e estrutura do objeto que comanda os procedimentos do pesquisador. O conselho tem validade para que se possa: "Alcançar a essência do objeto, isto é: capturando a sua estrutura e dinâmica, por meio de procedimentos analíticos e operando a sua síntese, o pesquisador a reproduz no plano do pensamento; mediante a pesquisa [...] começa-se pelo real e pelo concreto" (p. 22-42).

Cury (1989) interpreta de forma singular as categorias de pesquisa a partir de Marx: contradição, mediação, totalidade, além da práxis, o autor promove o diálogo dessas com o campo educacional guiado pelo desejo de transformação do que se pretende pesquisar.

Esse objeto de pesquisa buscou encontrar, após contato com o concreto, pontos contraditórios nas mediações com as referências teóricas pré-apresentadas e os que foram constituídos ao longo da caminhada acadêmica. 
Entretanto, uma advertência do autor surge como uma fonte de reflexão para analisar o que o campo a ser pesquisado possa revelar, em suas dinâmicas e seus pontos contraditórios, já que se trata de pesquisa no âmbito de instituições pedagógicas. Segundo o teórico, as instituições educativas são polos difusores das concepções de mundo de algum grupo social, por meio de ideias pedagógicas, que normalmente estão "A serviço de uma hegemonia ajudam a dar suporte à interiorização normativa na classe subalterna da concepção dominante, pelos mecanismos de articulação/desarticulação" (CURY, 1989, p. 94).

Até agora, foram expostas as grandes contribuições e possíveis colaborações conceituais do método de Marx, mas é importante neste momento promover o diálogo com outras correntes filosóficas e, embora haja várias, o texto irá deter-se em analisar as implicações que a perspectiva pós-moderna provoca nas pesquisas em educação.

Considera-se pertinente elencar alguns argumentos necessários para justificar o uso da teoria social e do método de pesquisa em Marx na educação, especialmente pela entrada acelerada do pensamento pós-moderno, pós-estruturalista, pós-colonialista, e tantos pós ${ }^{2}$ que trazem, sem dúvida, enormes avanços na produção do saber, mas que continuam a relativizar muitos temas caros para a concretude das relações sociais brasileiras. Quando o assunto é a relação econômica, social, cultural na e para a educação pública brasileira, essas concepções teóricas permanecem sem uma resposta concreta (SAVIANI, 2010; DUARTE, 2000) para os males que o sistema neoliberal capitalista continua a provocar nos países do globo.

\section{Sobre a atualidade do método materialista histórico dialé- tico}

Anderson (1992), ao analisar as diferentes correntes teóricas desde Hegel, que prenunciam o fim da história, defende ser possível afirmar que muitos sistemas econômicos e políticos tiveram o encerramento de um ciclo histórico, e embora as relações contemporâneas entre as nações não possam limitar-se a aceitar os desdobramentos do capitalismo como algo natural, sem contradições, o fato é que a própria história é quem traz o arcabouço de correntes teóricas e categorias que ajudam a compreender esta situação.

Wood (1999) revela que parte do mundo acadêmico assentado nos ideais pós-modernos e até mesmo alguns teóricos de esquerda anunciam a morte da história ou o triunfo final do capitalismo. $\mathrm{Na}$ verdade, são o reflexo de uma sociedade que apresenta "[...] um forte ceticismo epistemológico e profundo derrotismo político" (p. 124). E mais:

[...] proclamam o "fim da história" ou o triunfo final do capitalismo, certos intelectuais de esquerda nos dizem que uma época terminou, que vivemos numa era "pós-moderna": o "projeto do Iluminismo" está morto, todas as antigas vertentes e ideologias perderam sua relevância, os velhos princípios de racionalidade não valem mais, e assim por diante (WOOD, 1999, p. 120). 
No mesmo texto, Wood (1999) confirma a atualidade do uso do materialismo histórico dialético apontando que o próprio pós-modernismo tem fundações materiais possíveis de explicação objetiva:

\begin{abstract}
Não há, com efeito, melhor confirmação do materialismo histórico que o vínculo entre cultura pós-moderna e um capitalismo global segmentado, consumista e móvel. Nem tampouco uma abordagem materialista significa que temos que desvalorizar ou denegrir as dimensões culturais da experiência humana. Uma compreensão materialista constitui, ao contrário, passo essencial para liberar a cultura dos grilhões da mercantilização (p. 125).
\end{abstract}

Para o campo do currículo, a hegemonia atual das visões pós-modernas e pós-estruturalistas que marcam as teorias pós-críticas, tem resultado em poucas pesquisas que se preocupam com o desenvolvimento curricular na escola. Vale a pena pensar neste dilema a partir dos escritos de Young (2014):

O que é triste na área do currículo é que, como a teoria do currículo perdeu contato com seu objeto, há pouca pesquisa, não sabemos quase nada sobre como o currículo está sendo implementado nas escolas. Como os teóricos do currículo estão lendo os filósofos e as teorias literárias, eles não tratam dessa questão (p. 1117).

Vale refletir em Moreira (2012) as características e a relação do pensamento pós-moderno para o campo curricular que converge também para a proclamação da suposta morte da modernidade: a razão filosófica e científica moderna é colocada em suspeita; existe a rejeição de futuro, que, no pensamento moderno orienta as práticas do próprio currículo e, por fim:

[...] o discurso pós-moderno rejeita a ideia de educação como conscientização, como substituição de uma consciência ingênua por uma consciência crítica. Em último lugar, por desacreditar na existência de narrativas verdadeiras, a literatura pós-moderna valida provisoriamente todas as narrativas, o que implica a "celebração" da diferença, a equivalência das diferenças e das alteridades (p.17).

Não se trata de convencer o/a leitor/a de que a teoria crítica de Marx ou do currículo é o único caminho. Busca-se manter o diálogo com outros acadêmicos que ora beberam da fonte do marxismo e que hoje respiram outros ares, como defendem também Ribeiro; Veloso; Zanardi (2016): "[...] a teoria curricular crítica ainda tem muito a oferecer ao campo do currículo, sobretudo por se encontrar em diálogo com algumas contribuições pós-modernas e não estacionada em um cartesianismo estático como algumas vertentes pós-modernas insistem em rotular" (p. 257). Na verdade, é coletivamente que encontram-se saídas para pensar uma educação, a partir da escola, que seja centrada no sujeito, mas que não o desconsidere como pertencente a uma ordem social econômica mais ampla. Ambos os grupos em suas particularidades concordam com isso.

De forma didática, são esses os argumentos que justificam o uso teórico de Marx em detrimento de teorias que anunciem que sua perspectiva tenha findado: 
- A negação da superação do modo de produção capitalista, do sujeito, da razão, da história, da totalidade e do conhecimento objetivo traz o conformismo social e a supervalorização da luta por grupos e pulveriza a própria luta de classes (MALANCHEN, 2015). Anular a racionalidade e a objetividade é acreditar que a realidade é constituída de partículas "[...] e as relações do ser humano com o mundo são fortuitas. Em termos sociopolíticos, isso resulta na impossibilidade de elaboração de projetos e estratégias de ação coletiva no enfrentamento da lógica do capita"1. (MALANCHEN, 2016, p. 82).

- "[...] os problemas postos pelo marxismo são os problemas fundamentais da sociedade capitalista e enquanto estes problemas não forem resolvidos, superados não se pode falar que o marxismo terá sido superado" (SAVIANI, 2010, p. 17).

- Nesse sentido, a contrariedade das questões sociais brasileiras deve ser pautada sob o enfoque histórico-materialista que a própria teoria de Marx traz. Segundo ela "[...] o capitalismo continua sendo a forma social predominante. Portanto, Marx continua sendo não apenas uma referência válida, mas a principal referência para compreendermos a situação atual" (SAVIANI, 2010, p. 22).

- Se o pensamento de Marx estiver aberto à crítica "[...] abrindo mão de seu dogmatismo intrínseco [...] a teoria dialética da história tem condições morais e reais de funcionar como crítica permanente do modo de produção existente e temporariamente 'vigente'. Como fundador de um método dialético de análise, Marx ainda tem futuro" (FREITAG, 1993, p. 49).

- González (2006) é enfática ao defender a contemporaneidade do pensamento marxiano. Segundo ela, o capitalismo, ainda precisa ser interpretado pela ótica de Marx, porque "[...] um conhecimento rigoroso de suas teorias é condição necessária, embora não suficiente, para quem deseja compreender os acontecimentos fundamentais do século XIX até nossos dias" (p. 17).

- Marx e Engels, em sua própria época histórica, já alertavam para os perigos das apropriações a-históricas e descontextualizadas de suas reflexões, sendo que o recado foi direcionado para os seguidores e opositores e ainda em tempos contemporâneos encontramos muitos que "confirmam" a morte do marxismo, quer pela suposta derrota de suas ideias, quer pela impossibilidade de subserviência às doutrinas filosóficas da modernidade. Para eles, o marxismo, segundo Amadeo (2006), deve ser atual porque ainda vive a práxis que o criou e o sustenta, e poderá acabar: "Por essas razões, o marxismo continua sendo a filosofia insuperável de nosso tempo, porque as circunstâncias que o engendraram não foram superadas" (grifos dos autores, p. 93).

- Segundo Hobsbawm (1998), quanto ao futuro previsível, é preciso defender Marx e o marxismo dentro e fora da história contra aqueles que os atacam no terreno político e ideológico. Ao fazer isso, também estarão defendendo a história e a capacidade do homem de compreender como o mundo veio a ser o que é hoje e como a humanidade pode avançar para um futuro melhor. 
- Boron (2006) apresenta um argumento justificável para o uso da epistemologia marxiana e marxista como lente teórica no entendimento das grandes questões da sociedade capitalista. Para ele, somente com o marxismo não se conseguirá transformar a realidade disforme e desigual do Brasil, mas sem o marxismo tampouco esse quadro se modificará.

Lembre-se que Marx não trouxe um conceito para história porque seu objeto era outro. Na verdade, há em torno da história, segundo Chauí (2006), uma poderosa possibilidade de utilização ideológica para compreensão de qualquer objeto pesquisado.

A sugestão de Wood (2006) é valorosa e sustenta as leituras acerca da presença da História nos currículos da educação básica, já que tanto Marx, quanto a teoria crítica de educação e currículo lutam pela emancipação do sujeito, resultando na democratização de todos os espaços, sobretudo o político. Novamente a caminhada pelo materialismo histórico dialético é confirmada:

\begin{abstract}
[...] o capitalismo é - em sua análise final - incompatível com a democracia, se por "democracia" entendermos tal como o indica sua significação literal, o poder popular ou o governo do povo. Não existe um capitalismo governado pelo povo no qual o desejo das pessoas seja privilegiado aos dos imperativos do ganho e da acumulação e no qual os requisitos da maximização do benefício não ditem as condições mais básicas de vida. (p. 382).
\end{abstract}

Na próxima seção, propõe-se um diálogo entre o objeto específico de pesquisa e a utilização do materialismo histórico dialético, a título de exemplo e discussão.

\title{
Um exemplo: a relação do objeto de pesquisa com o método de Marx aplicado ao campo curricular
}

A partir da análise da realidade concreta de algumas instituições privadas de ensino superior pretendeu-se compreender a relação entre as três principais categorias de pesquisa: Pedagogia, currículo e ensino de História, mas em que espaço? Nas instituições de ensino superior responsáveis pela formação inicial dos futuros pedagogos -onde deveria ocorrer o desenvolvimento de conhecimentos emanados da ciência histórica - pois, segundo Marx (1982) [1859], é ela (a História) quem explica e consegue conectar o próprio conhecimento humano com vistas a sua própria transformação: da realidade vivida e da sabedoria acumulada pela humanidade, nota-se a importância singular da História enquanto ciência epistemológica.

Conforme Saviani (2011), não basta selecionar trechos da obra de Marx e Engels que se referem à Educação para se constituir uma pedagogia marxiana, tampouco analisar as implicações educacionais dos fundadores do materialismo histórico, já que "[...] nem toda teoria marxiana da educação pode ser considerada pedagogia" (p. 22). O filósofo defende que uma pedagogia socialista baseada no "socialismo científico" de Marx e Engels só se constitui caso penetre no interior dos processos pedagógicos e tome a prática social como ponto de partida e de chegada, num movimento dinâmico, como acredita-se. Sua pedagogia histórico-crítica trilha este caminho quando tenciona problematizar os grandes dilemas educacionais, como também formular diretrizes que reorientem a prática educativa. Assim: 
[...] a pedagogia socialista compatível com o marxismo será aquela que, fundando-se na perspectiva do "socialismo científico", busque equacionar o problema da relação professor-aluno, orientando o modo como se deve realizar o processo de ensino e aprendizagem, como tudo o que essa ação implica e que deverá ser sistematizada na teoria pedagógica correspondente (p.22).

Concorda-se e acrescenta-se: que os currículos em todos os níveis escolares possam oferecer de fato uma formação integral e integrada, e por que não a partir da disciplina História? A aposta que é lançada é de que seria este um passo ousado para o desmantelamento da sociedade tão desigual que ainda nos cerca, na melhor acepção do que defende Young (2007): uma prática curricular assentada em "conhecimentos poderosos" que por si só justificam a necessidade existencial da escola e sua utilidade em superar o que o autor denomina de "conhecimento dos poderosos":

[...] é que elas capacitam ou podem capacitar jovens a adquirir o conhecimento que, para a maioria deles, não pode ser adquirido em casa ou em sua comunidade, e para adultos, em seus locais de trabalho. [...] O 'conhecimento dos poderosos' é definido por quem detém o conhecimento [...] É esse conhecimento independente de contexto que é, pelo menos potencialmente, adquirido na escola e é a ele que me refiro como conhecimento poderoso (p. 1294-1296).

Definem-se como "conhecimento poderoso" (Young, 2007) para os currículos de Pedagogia no âmbito do ensino de História as seguintes assertivas: reconhecer o objeto de estudo da História e seus métodos de produção de conhecimento; desenvolver plenamente as categorias centrais que sustentam a História como sujeito, fonte, fato, documento e tempo histórico; debate sobre as diferentes correntes historiográficas; estudar a historiografia brasileira e a história da disciplina História nos currículos dos anos iniciais do ensino fundamental; desenvolver práticas integradas que favoreçam a elaboração de uma concepção própria de História pelos estudantes de Pedagogia e realizar ações didáticas inerentes aos anos iniciais que garantam formação ampla e crítica dos estudantes. Sobre esse tema, Malanchen (2016) é enfática ao definir o espaço da escola e sua finalidade, sublinhando que as instituições de ensino devem desviar-se de práticas cotidianas e espontaneístas e primar para que sejam:

[...] intencionais e planejados, entendendo que não há um conhecimento que pertença à burguesia e outro à classe trabalhadora. No entanto, o que ocorre é uma apropriação pela classe dominante dos conhecimentos científicos que são empregados pela ideologia dessa classe. Porém, quando forem de domínio da classe trabalhadora, esses conhecimentos poderão assumir outras características e finalidades (p. 181).

O currículo apontado por Young parte do conhecimento e não do aluno, porque concebe que o conhecimento do estudante situa-se em uma base social histórica que não é dada, mas dinâmica: "[...] as crianças precisam de conhecimento poderoso para compreender e interpretar o mundo. Sem eles, permanecem dependentes daqueles que os têm [...] é justo que todas as crianças devam ter acesso a esse conhecimento" (YOUNG, 2014, p. 13, tradução deste autor). Young (2014c) destaca ainda que: “[...] um currículo que incorpore o conhecimento poderoso é um currículo que se concentra 
no conhecimento ao qual os jovens não têm acesso em casa. É distinto da experiência pessoal deles e, essencialmente, desafia essa experiência" (p. 1118). Defender essa posição diante do quadro atual de políticas curriculares supostamente progressistas é complexo, embora elas resultem em currículos que servem apenas para prestar contas em vez de ser um elemento norteador para professores. A respeito desse assunto, Young (2011) observa que:

Parece que as diretrizes presumem que a solução para a falta de motivação dos estudantes seja dar mais orientação curricular para os professores, em vez de fortalecer e apoiar seu conhecimento pedagógico e da matéria e, consequentemente, seu profissionalismo (p. 613).

Ainda sobre a necessidade de um currículo baseado no "conhecimento poderoso”, Young (2011) justifica por que os documentos e as práticas curriculares não podem ser baseados apenas em conteúdos e habilidades, no cotidiano ou na cultura, que supostamente o aluno já possua, já que o mesmo, não vai à escola para aprender o que já sabe, ao contrário, o conhecimento curricular deve basear-se na produção científica de cada campo de pesquisa.

Como também ponderou Young (2007), é preciso lembrar que a contribuição de Marx não se restringe ao campo metodológico. Para Japiassu (1978), sua reflexão do papel desalienante da História enquanto ciência emancipadora - o que confirma, em parte, a tese ora proposta - precisa ser mais bem estudada e não pode conformar-se com um currículo centrado no cotidiano apenas.

Embora Marx não tenha sido um teórico educacional, seus escritos influenciaram profundamente outros intelectuais, como Gramsci, e mudaram os rumos de muitos países no século XIX, principalmente.

Moraes (2014), analisando o papel da consciência no método de pesquisa em Marx, revela a atuação de Gramsci na elaboração de tantas reflexões sobre o vigor que o marxismo teve e continua a ter sobre os trabalhadores em seus vínculos com a educação. Segundo a autora, é urgente que as massas se organizem numa contra-hegemonia que liberte suas consciências, criando uma nova cultura com novos valores, uma nova ordem social.

É este o papel da escola unitária que o italiano defendia quando se referia à instrução que deveria unir trabalho manual e intelectual, além de aumentar corpo docente no intuito de garantir escolarização de qualidade para o maior número de pessoas, sem esquecer-se da infraestrutura predial de uma escola desse porte, que deveria contar com bibliotecas especializadas, dormitórios, salas de seminários. Sobre isso, vale a pena resgatar o pensamento, de Gramsci (1982, p. 121-122-123):

A escola unitária ou de formação humanista (entendido este termo, "humanismo", em sentido amplo e não apenas em sentido tradicional) ou de cultura geral deveria se propor a tarefa de inserir os jovens na atividade social, depois de tê-los levado a um certo grau de maturidade e capacidade, à criação intelectual e prática e a uma certa autonomia na orientação e na iniciativa [...] A escola unitária 
requer que o Estado possa assumir as despesas que hoje estão a

cargo da família.

Não restam dúvidas de que a centralidade do ensino de História na formação inicial de pedagogos é premissa basilar para o cumprimento de tal projeto. E antes que muitos teóricos acusem a proposta marxista de ser rígida, criadora de protótipos, ou ainda que tenha com uma tendência ser uma fórmula mágica, é preciso lembrar que tal concepção não conseguiu materializar-se em nenhuma sociedade, portanto, pensar nessa visão contra-hegemônica é ceder à tentação da utopia moderna, que na prática exportou para o mundo ocidental o modelo de escola "afrancesada" de caráter dualista e típico nos moldes da ordem capitalista burguesa sob o pretexto de oferecer uma instrução superficial e compensatória para a maior parte da população. Essa sim é uma realidade, não homogênea ou estática, mas com forte adesão por aqui e que pouco contribui para a emancipação dos sujeitos. Anseio que ainda é contemporâneo e alimenta muitos entusiastas de uma escola que seja, de fato, crítica.

\section{Considerações finais}

Analisar o objeto proposto a partir da tese - de que o ensino de História deva ser relevante nos currículos de formação do pedagogo - direciona esses escritos para a análise reflexiva sob a lente teórico-metodológica do materialismo histórico dialético. Não se assume uma postura de concebê-lo como doutrina, reconhece-se seus limites, mas admite-se que ainda é a tendência que melhor se aproxima da questão central de pesquisa e de muitas outras.

Não se pode querer promover um diálogo harmonioso entre o MHD e qualquer problema ou objeto de pesquisa, na verdade método de investigação científica deve cumprir a função de ser a lente teórica sob a qual o pesquisador enxerga de forma ampliada as inúmeras determinações que sua investigação pode levar. É preciso admitir que os estudos comparados, a fenomenologia, os estudos culturais e tantos outros percursos metodológicos têm seu valor e respondem de forma sólida muitas questões de pesquisa. $\mathrm{O}$ mais importante nessa seara é manter a coesão e a coerência teórica entre problema, objeto, método, metodologia, teoria e epistemologia. Em se tratando de pesquisas no campo do currículo, essa advertência é crucial para garantir solidez nas sínteses delineadas pelos mestres e doutores em Educação.

Doravante, é inadmissível que se trate de forma natural o escasso tempo que os pesquisadores (mestrando e doutorandos) têm em sua trajetória acadêmica para aprofundar-se nas leituras sobre os métodos de pesquisa em Ciências Humanas e Sociais, o caso da Educação é peculiar, porque se trata de uma área do conhecimento que necessita da contribuição de vários campos para que se chegue a reflexões parciais e sínteses superadoras.

Reitera-se que o uso do MHD de forma irresponsável, superficial ou como profissão de fé em nada contribui para fazer avançar a problemática aqui estudada. 


\section{Referências}

AMADEO, Javier. Mapeando o marxismo. In: BORON, Atílio A.; AMADEO, Javier; GONZÁLEZ, Sabrina (Orgs.). A teoria marxista hoje: problemas e perspectivas. Buenos Aires: CLACSO; Expressão Popular, 2006.

ANDERSON, Perry. O fim da história: de Hegel a Fukuyama. Rio de Janeiro: Jorge Zahar Ed., 1992.

BORON, Atílio A. Aula Inaugural: pelo necessário (e demorado) retorno ao marxismo. In: BORON, Atílio A.; AMADEO, Javier; GONZÁLEZ, Sabrina (Orgs.). A teoria marxista hoje: problemas e perspectivas. Buenos Aires: CLACSO; Expressão Popular, 2006.

CHAUÍ. Marilena. A História no pensamento de Marx. In: BORON, Atílio A.; AMADEO, Javier; GONZÁLEZ, Sabrina (Orgs.). A teoria marxista hoje: problemas e perspectivas. Buenos Aires: CLACSO; Expressão Popular, 2006.

CURY, Carlos Roberto Jamil. Educação e Contradição: elementos metodológicos para uma teoria crítica do fenômeno educativo. São Paulo: Cortez, 1989.

DUARTE, Newton. Vigotski e o "aprender a aprender”: crítica às apropriações neoliberais e pós-modernas da teoria vigotskiana. Campinas: Autores Associados, 2000.

FREITAG, Barbara; PINHEIRO, Maria Francisco (Orgs.). Marx morreu: Viva Marx!. Campinas: Papirus, 1993.

FRIGOTTO, Gaudêncio. O enfoque da dialética materialista histórica na pesquisa educacional. In: FAZENDA, Ivani (Org.). Metodologia da pesquisa educacional. São Paulo: Cortez, 2010.

GANEN, Angela. Karl Popper versus Theodor Adorno: lições de um confronto histórico. Revista de Economia Política, vol. 32, n. 1 (126), p87-108, janeiro-março/2012.

GIL, Antônio Carlos. Métodos e Técnicas de Pesquisa social. 6a. Ed. São Paulo: Atlas, 2009.

GONZÁLEZ, Sabrina. Crônicas marxianas de uma morte anunciada. In: BORON, Atílio A.; AMADEO, Javier; GONZÁLEZ, Sabrina (Orgs.). A teoria marxista hoje: problemas e perspectivas. Buenos Aires: CLACSO; Expressão Popular, 2006.

GRAMSCI, Antonio. Os Intelectuais e a Organização da Cultura. Civilização Brasileira S.A. RJ. 1982.

HOBSBAWM, Eric. Sobre história. São Paulo: Companhia das Letras, 1998.

JAPIASSU, Hilton. Interdisciplinaridade e patologia do saber. Rio de Janeiro: Imago, 1976.

LUKÁCS, Geörg. Ontologia do ser social. In: LUKÁCS, Geörg. Os princípios ontológicos fundamentais de Marx. Trad. de Carlos Nelson Coutinho. São Paulo: Ciências Humanas, 1979.

MALANCHEN, Julia. Cultura, Conhecimento e Currículo: contribuições da pedagogia histórico-crítica. Campinas, SP: Autores Associados, 2016.

MALANCHEN, Julia. Pedagogia Histórico-Crítica e saber objetivo versus multiculturalismo e o relativismo no debate curricular atual. Revista Germinal: Marxismo em debate, Salvador, v. 7, n. 1, p. 26-43, jun. 2015.

MARX, Karl. ENGELS Friedrich. Manifesto do Partido Comunista. São Paulo: Expressão Popular [1848], 2008.

MARX, Karl. ENGELS Friedrich. Contribuição para a Crítica da Economia Política. (Trad. Maria Helena Barreiro Alves). São Paulo: Mandacaru, 1989.

MARX, Karl. ENGELS Friedrich. Prefácio do Capital. 1a Edição: [1867]. Centelha - Promoção do Livro, SARL, Coimbra, 1974. 
Materialismo histórico e dialético em pesquisas do campo curricular: o ensino de História no curso de Pedagogia

MARX, Karl. ENGELS Friedrich.Prefácio. In: MARX, Karl. Para a crítica da economia política. Lisboa: Edições Progresso; Moscovo, 1982 [1859].

MORAES, Raquel de Almeida. O método materialista dialético e a consciência. In: CUNHA, Célio da; Sousa, José vieira de; SILVA, Maria Abadia. O método dialético na pesquisa em Educação. Campinas, SP: Autores Associados/ Brasília, DF: Faculdade de Educação, Universidade de Brasília, UnB, 2014.

MOREIRA, Antonio Flavio Barbosa. Currículo: questões atuais. Campinas: Papirus, 2012.

NETTO, José Paulo. Introdução ao estudo do método de Marx. São Paulo: Expressão Popular, 2011.

PUCCI, Bruno. Teoria Crítica e Educação. In: PUCCI (Org.). Teoria Crítica e Educação: a questão da formação cultural na Escola de Frankfurt. Petrópolis, RJ: Vozes; São Carlos, SP: EDUFSCAR, 2007.

RENAULT, Emmanuel. Vocabulário de Karl Marx. Trad. de Claudia Berliner. São Paulo: Editora WMF Martins Fontes, 2010.

RIBEIRO, Márden de Pádua; VELOSO, Silene Gelmini Araújo; ZANARDI, Teodoro Adriano Costa. Fim da Teoria Crítica? Crítica aos extremos pós-modernos e pós-estruturais da teoria curricular. Revista Currículo sem Fronteiras, v. 16, n. 2, p. 255-282, maio/ago. 2016.

SAVIANI, Dermeval. Prefácio à edição brasileira. In: MANACORDA, Mario Aligheiro. Marx e a pedagogia moderna. Campinas: Alínea, 2010.

SAVIANI, Dermeval. Marxismo e Pedagogia. Revista HISTEDBR On-Line, Campinas, número especial, p. 16-27, abr. 2011.

SILVA, Tomaz Tadeu da. Documentos de identidade: uma introdução às teorias do currículo. Belo Horizonte: Autêntica, 2011.

TRIVIÑOS, Augusto N. S. Introdução à pesquisa em ciências sociais: a pesquisa qualitativa em educação. São Paulo: Atlas, 2011.

WOOD, Ellen Meiksins. "O que é a agenda "pós-moderna”?". In: WOOD, Ellen Meiksins \& FOSTER, John Bellamy (Orgs.). Em Defesa da História: marxismo e pós-modernismo. Trad.: Ruy Jungmann. Rio de Janeiro, Jorge Zahar, 1999.

YOUNG, Michael. Para que servem as escolas? Revista Educ. Soc., Campinas, vol. 28, n. 101, p. 1287-1302, set./dez. 2007.

YOUNG, Michael. Michael Young e o campo do currículo: da ênfase no "conhecimento dos poderosos" à defesa do "conhecimento poderoso". (Entrevista). GALLAN, Cláudia Valentina Assumpção; LOUZANO, Paula Baptista Jorge. Revista Educação e Pesquisa, São Paulo, v. 40, n. 4, p. 1109-1124, out./dez. 2014.

YOUNG, Michael. O futuro da educação em uma sociedade do conhecimento: o argumento radical em defesa de um currículo centrado em disciplinas. Revista Brasileira de Educação. V. 16, n. 48, set.-dez. 2011.

\section{Notas}

1 Disponível em: <http://analisevisual.capes.gov.br/SASVisualAnalyticsViewer/VisualAnalyticsViewer guest.jsp? report Name $=\mathrm{B}$ anco + de + Teses+e+Disserta $\% \mathrm{C} 3 \% \mathrm{~A} 7 \% \mathrm{C} 3 \% \mathrm{~B} 5 \mathrm{es}+-+$ Informa\%C3\%A7\%C3\%B5es+quantitativas\&reportPath=/DTI/Banco_de_teses_e_dissertacoes/Relatorios\&reportViewOnly=false\&appSwitcherDisabled=true $>$. Acesso em: 18/10/2017. 
${ }^{2}$ As principais características das teorias do campo educacional que baseiam seus escritos na pós-modernidade são: crença no fim da era moderna e do ideal de homem/sociedade iluminista; confiança no fim das metanarrativas. Moreira (2012, p. 10) acrescenta: “[...] descrença em uma consciência unitária, homogênea, centrada; rejeição da ideia de utopia; preocupação com a linguagem e com a subjetividade; a visão de que todo discurso está saturado de poder e a celebração da diferença”.

* Professor doutor do do Centro Universitário Projeção, Brasília, Distrito Federal, Brasil.

** Diretora da Faculdade de Educação da Universidade de Brasília, Brasília, Distrito Federal, Brasil.

\section{Correspondência}

Francisco Thiago Silva - Centro Universitário Projeção. Quadra CNB 14 Lotes 7/8/9 Taguatinga Norte (Taguatinga). CEP: 72115145. Brasília, Distrito Federal, Brasil.

E-mail: fthiago2002@yahoo.com.br-liviaffb@terra.com.br

Recebido em 19 de outubro de 2017

Aprovado em 10 de abril de 2018 